\title{
Analysis On the Process and Influencing Factors of Nimby Risk Diffusion in 'One Belt And One Road' Energy Investment
}

\author{
Jinhua Sun *, Linlin $\mathrm{Xu}$, Dong Pu, Jian $\mathrm{Hu}$ \\ Chongqing University of Technology, 69 hongguang avenue, Chongqing, China \\ Sjh1009@163.com
}

\begin{abstract}
Based on the chain structure diffusion of nimby risk and the theory of risk social amplification, this paper proposes the adjacent diffusion processes of risk avoidance, risk explosion stage and risk disappearance stage, analyzes the action mechanism of each stage, and constructs a risk avoidance diffusion process model. Finally, based on the existing research achievements of risk avoidance, the factors affecting nimby risk diffusion are summarized from five aspects: host residents, host government, construction enterprises, social media and social environment.
\end{abstract}

Keywords: One Belt And One Road, Nimby Risk, Energy Investment

\section{INTRODUCTION}

In May 2017, China 's National Development and Reform Commission and the National Energy Administration jointly issued the "Wills and Actions to Promote Energy Cooperation in the Silk Road Economic Belt and the 21st Century Maritime Silk Road", proposing the establishment of a "One Belt And One Road" energy cooperation platform to involve more countries in energy cooperation projects. However, the overseas energy investment environment is becoming more and more complex, and many host countries have many residents protesting against the energy projects of Chinese enterprises, leading investors to terminate energy cooperation. For example, the Sino-Myanmar oil pipeline project, which started construction in October 2013, was forced to suspend work for two years due to the opposition of the people along the route. In September 2016, the Belgian National Security Agency warned the Belgian government "being cautious of China 's intention to acquire the Belgian power grid will cause damage to the country" on the grounds of threats to national security. Under the "Belt and Road" initiative, a large number of energy companies in China will "go out" to invest in the future. At this stage, these "neighborhood" incidents are still rare, but there may be a large number of "neighborhood" incidents in the future. These incidents may lead to huge losses of China's energy companies' overseas investments. Therefore, how to avoid the losses caused by nimby risk and how to control the spread of $\mathrm{n}$ nimby risk at the source are urgent issues that need to be resolved.

\section{ANALYSIS ON THE STAGE OF NIMBY RISK DIFFUSION}

Under the vigorous implementation of the "Belt and Road" initiative, it is imperative for energy-based enterprises to go out and invest. How to reduce the risk loss suffered by enterprises investing abroad is the key issue that enterprises need to solve in order to go out safely and invest. Based on the chain structure of nimby risk diffusion [1] and the four-stage model of nimby risk society amplification [2], this paper proposes the process of nimby risk diffusion, which is divided into three stages: generation stage, explosion stage and disappearance stage.

\subsection{The generation stage of nimby risk}

At the stage of the generation of the nimby risk, due to the negative externality of the neighbor avoidance project constructed by the company's energy investment in the host country, the residents of the nearby host did not have any perception at first. When the destruction occurred, the health of nearby residents was affected, and they gradually sensed the risk of negative externalities caused by neighboring facilities, and began to feel anxious and unfair. As this emotional backlog and some rumors began to spread, host residents began to think that corporate energy investment was a disguised act of plundering their own resources, and that the energy facilities they built were extremely harmful to the surrounding residents 'environment and health A host of residents began to organize a "walk" on the street spontaneously to protest the construction of the neighbor avoidance project. However, due to the consideration of local fiscal revenue, the host government will not choose to stop the construction of energy investment projects, but choose to ignore the protesters and continue to operate. The "walking" behavior of the host residents has attracted the attention of social media, and the negative reports of the news about the neighbor avoidance project continue to increase. With the popularization of mobile phones and $5 \mathrm{G}$ networks, the new media has also contributed to the spread of information. Rumors about the neighbor avoidance 
project spread quickly on the social network. At the same time, host residents who do not live near the nimby project have learned the negative news about the nimby facilities from the news media, and have actively participated in the opposition to the construction of the nimby facilities. The public reported the nimby problem to the host government, which failed to solve it in a timely manner, and the host residents' pent-up resentment was on the verge of being ignited.

\subsection{The outbreak stage of nimby risk}

The outbreak stage is the key to control the spread of nimby risk. At this stage, due to inaction, the credibility of the host government has dropped significantly, and the host residents will also have a sense of distrust towards the construction of the enterprise, and the disgust and resistance in their hearts will peak, and various rumors on the Internet will fly. The negative news of the project continued to grow, and the host residents took to the streets to resist the construction of nimby facilities in order to protect their own interests. At this time, the host government took relevant measures to suppress the protest, which intensified the conflicts. Finally, the nimby conflict broke out and even led to bloodshed. At the peak of nimby conflict, construction enterprises had to stop operating and chose to suspend operations for rectification due to the pressure from host residents and NGOs. Out of consideration for GDP, host governments began to compromise with host residents that offering considerable compensation and proper communication. At this point, some residents will choose to accept the government's compensation, while others will continue to protest until the government gives a positive response and proposes a solution. In the late stage of the outbreak, the nimby conflict became more and more intense, and the host government and construction enterprises had to increase the degree of information disclosure and compensation. After receiving the response from the host government and the compensation in line with the psychological expectation, the residents' resistance to nimby began to decrease, the degree of nimby conflict also eased to some extent, and the diffusion rate of nimby risk also eased.

\subsection{Stage of vanishing risk}

Since the host government and the construction enterprise took the correct measures in the late stage of the outbreak, the diffusion rate of risk aversion in the disappearance stage will decrease as the resistance of the host residents declines, until the host residents pass the science of building the enterprise and the host government 's Information disclosure, a new understanding of the risks caused by the negative externalities of the projects under construction, after their psychology no longer has resistance to nimby facilities, and nimby risks will no longer continue to spread. It can be seen that in the whole process of nimby risk diffusion, if construction enterprises and host governments increase information disclosure at the generation stage of nimby risk, give host residents psychological expected compensation and construction enterprises fulfill their social responsibilities, there will be no nimby conflict.

\section{ANALYSIS OF KEY INFLIUENCING FACTORS OF NIMBY RISK DIFFUSION}

The process of nimby risk diffusion is a very complex dynamic process. From the generation of risk to the disappearance of risk, it is influenced and controlled by multiple factors, which exert a strong influence on the whole process of its generation and diffusion. Improper control may lead to the occurrence of nimby conflict and bring huge losses to the enterprise. Therefore, understanding the main factors that influence the whole process of nimby risk diffusion is of great significance to the study of the mechanism of nimby risk diffusion. Scholars have studied the factors that influence nimby risk from different perspectives, which are mainly classified into five categories: host residents, host government, social media, construction enterprises and environmental factors.

\subsection{Host residents factor}

As the most important subject of nimby risk, host residents are also the focus of nimby event research. At present, it is generally believed in the academic circles that the main reason for the phenomenon of nimby is that nimby facilities not only bring convenience to all residents, but also have a negative impact on residents around the facilities. Such uneven distribution of benefits leads to a sense of unfairness among residents around the facilities and hence resistance. Scholars Hong Fang and wang Zheng studied environmental mass incidents from the perspective of public psychological needs, discussed the psychological formation mechanism of the public psychological occurrence of mass incidents, and divided the public psychological needs into four aspects: security needs, interest needs, information needs and justice needs [3]. In addition, the benefits of the government and construction enterprises to the residents compensation is also an important factor affecting the psychological factors of the public. Zhang Jing et al. believe that monetary compensation, public facility compensation, and ecological compensation have the mechanism of enhancing personal and public interests and creating an environmentally friendly ecosystem. Appropriate compensation for personal benefits to residents near neighboring facilities can increase residents ' Satisfaction with the government and enterprises, thus effectively alleviating their psychological resistance [4].

\subsection{Host Government Factor}

In the whole process of nimby risk diffusion, host government is often the direct cause of the nimby movement. 
Whether the nimby risk spreads lies in whether the host government is willing to actively handle the neighbor avoidance event. Because the host government has the right to monopolize neighbor conflict avoidance governance and conceal neighbor avoidance facility location decision-making, it often chooses to passively handle the neighbor avoidance event. On the governance issue of neighbor-to-avoidance conflicts, the host government 's governance logic is often to choose a "bottom governance government". As for the solution to the problem of evasion, we cannot always rely on consultative democracy and the construction of civil society. The government must enhance its credibility, reduce invalid government actions, and enhance public communication. Xin Fangkun built a four-stage model of adjacency social amplification based on the theory of risk society amplification, deconstructed the process of government trust loss, and found that the government trust dissolution in the aversion crisis is caused by the superposition of multiple factors such as information imbalance and response failure [5].

\subsection{Social media factor}

Neighboring facilities have attracted the attention of social media when they were first built, and through television news, newspaper reports and new online media reports, a large number of information shocks have made it impossible for host residents to distinguish true and false when facing rumors, thus Affect the judgment of the host residents. The spread of rumors has also made the public opinion environment more complicated, and the host residents have become more emotional and extreme, which has increased the deterioration of neighbor-avoidance conflicts. Deng jiwen et al. believed that the insufficient response of the government could promote the diffusion of anxiety and fear among residents of the host country. In addition, with less communication with residents, it was easier to generate a negative public opinion atmosphere about the construction of enterprises and nimby facilities [6]. Liu liang et al. believe that public satisfaction, residents' attention, media attention and other factors have a great impact on the spread of nimby risks [7].

\subsection{Building the enterprise factor}

Before the outbreak of nimby risk, enterprises usually adopt concealment strategy for their own interests. Until the outbreak of nimby conflict and the loss of their interests, they will try to manage the nimby event and reduce their own losses. However, such after-the-fact decisions tend to bring greater losses to enterprises. Therefore, scholars have found that increasing CSR of construction enterprises before building energy facilities can effectively mitigate the occurrence of nimby conflicts and contain the spread of nimby risks. Constructing enterprises to spread popular science knowledge to nearby residents and respond to environmental problems caused by neighboring facilities can enhance public trust in the establishment of enterprises, reduce public doubts and panic about neighboring facilities, and improve the scientific literacy of the public, thus rationally Understand the real risks arising from neighboring facilities and suppress the generation and spread of rumors [8].

\subsection{Social environmental factor}

At present, scholars mainly believe that socio-economic risk, socio-political risk, legal system risk and social democracy degree will have an impact on the spread of neighbor avoidance risk. Wu Zongyun et al. believed that the rapid development of the social economy has improved the knowledge level of the residents. With the enhancement of the public's awareness of environmental protection and rights protection, the host residents no longer accept the government's monopoly on the decision to avoid the incident, thus causing a resistance Event [9]. Wang Hui et al. Found that the construction of the legal system directly affects the improvement of the supervision mechanism by studying the case of Hengka Company v. US Government, which is a typical large-scale neighbor avoidance conflict. Unblocked, thus causing negative public perception of the host government and the establishment of enterprises, it is more likely to cause the occurrence of neighbor avoidance events [10]. The higher the degree of democracy in the host country, the stronger the democracy of the host residents, and the easier it is to "go on the street" or even resist the neighboring facilities because of the unfairness of the negative externalities of the neighboring facilities. It is a direct threat to the investment security of enterprises, and there have been many cases of heavy losses in energy investment due to terrorism in the host country.

\section{CONCLUSION}

In this paper, the nimby risk is incorporated into the overseas energy investment risk system. Based on the theoretical basis of relevant literature, combining the chain spread characteristics of risk avoidance and the theory of social risk amplification, a three-stage model of the spread of nimby risk is innovatively proposed. It also analyzes the main tasks, goals and corresponding action mechanisms of each stage, and builds a mechanism model for neighbor risk avoidance. The key elements that influence the process of neighbor risk avoidance are summarized from the five main bodies of the host resident, host government, construction enterprise, social media and social environment.

\section{ACKNOWLEDGMENTS}

This work is supported by the Humanity and Social Science Youth Foundation of Ministry of Education of China (Grant No. 19YJCZH054), 
the project of science and technology research program of Chongqing Education Commission of China (No. KJQN201801145) and the Chongqing Social Science Planning Project (Grant No. 2015YBSH051).

\section{REFERENCES}

[1] Y.Q. Wu, L. Luo.(2018) Spatial effect analysis of urban neighboring facilities based on housing prices-Taking Nanjing Lanyan Sanchao gas station as an example. Regional research and development, 37:78- 82.

[2] Q.N. Zhao, J. Xiao, M.L. Liu and L.J. Fan.(2019) Research on the influence of neighboring facilities on the price of surrounding housing_-Taking Hefei funeral home as an example. City planning, 43:107-112.

[3] F. Hong and Z. Wang.(2014) Analysis of public psychological needs in environmental group incidents. Journal of china environmental management college, 24:5-7.

[4] J. Zhang and Y.F. Shang.(2019) Research on energy efficiency of benefit aggregation of the neighbor avoidance compensation feedback mechanism. Leadership science, 7-11.

[5] F.K. Xin.(2018) Government trust in the process of risk aversion society amplification: from loss to reconstruction. Chinese administrative management, 126-131.

[6] J.W. Deng and H.M. Niu.(2018) The generation logic of urban environmental aversion risk in china-Analysis based on case embedding. Journal of central south university of forestry and technology (social science edition), 12:1-7.

[7] L. Liu, Y. Shen, X.Y. Cao J. He and S.M. Li.(2012) Research on unconventional emergency warning model based on key information. Management review, 24:166-176.

[8] J. Lu.(2015) Analysis of the role and path of popular science propaganda in resolving conflicts between neighbors and avoidance. Communication and copyright, 182-183.

[9] Z.Y. Wu, Y.H. Song, W. Lv and D.H. Fang. (2017) Influencing factors and relational structure of neighboring group events in china. Chinese journal of safety science, 27:169-174.

[10] H. Wang and J.F. Yu. (2017) The legal enlightenment of Hengka company v. U.S. government on china 's response to environmental conflict avoidance. Environmental protection, 45:72-75. 